\title{
Differential Effects of Short- and Long-Term Potentiation on Cell Firing in the CA1 Region of the Hippocampus
}

\author{
Carrie P. Marder and Dean V. Buonomano \\ Departments of Neurobiology and Psychology, and Brain Research Institute, University of California, Los Angeles, Los Angeles, California 90095
}

Long-term potentiation (LTP) in the hippocampus enhances the ability of a stimulus to produce cell firing, not only by increasing the strength of the EPSPs, but also by increasing the efficiency of the input/output (I/O) function of pyramidal neurons. This means that EPSPs of a given size more easily elicit spikes after LTP, a process known as EPSP-spike (E-S) potentiation. In contrast to LTP, it is not known whether the synaptic strengthening produced by paired-pulse facilitation (PPF) also results in changes in the I/O function. We have addressed this question by examining E-S curves from rat hippocampal area CA1 in response to both PPF and LTP. We describe a novel form of I/O modulation in which PPF produces E-S depression; that is, the E-S curve is shifted to the right, indicating a decreased ability of EPSPs to elicit action potentials. Consistent with the notion that E-S potentiation observed with LTP is caused by long-term increases in the excitatory-inhibitory ratio, we show that PPF-induced E-S depression relies on short-term decreases in this ratio. These results indicate that different forms of synaptic plasticity that produce the same degree of EPSP potentiation can result in dramatically different effects on cell firing, because of the dynamic changes in the excitatory-inhibitory balance within local circuits.

Key words: hippocampus; CA1; inhibition; EPSP-spike potentiation; long-term potentiation; paired-pulse facilitation; input/output; circuit

\section{Introduction}

An understanding of how neural networks process information requires insights into the mechanisms whereby synaptic inputs translate into firing patterns. Whether a neuron fires in response to a stimulus depends not only on the strength of the excitatory synapses, but also on intrinsic cellular properties and the net balance between excitation and inhibition. It is therefore important to understand how plasticity affects the state of the network as a whole during short-term forms of synaptic plasticity such as paired-pulse facilitation (PPF), as well as long-term forms of plasticity.

Long-term potentiation (LTP) is a long-lasting enhancement in synaptic efficacy regarded as the neural basis for learning and memory. LTP can be observed extracellularly as an increase in the size of the field EPSP (fEPSP), as well as an increase in the size and decrease in the latency of the population spike (Bliss and Gardner-Medwin, 1973; Bliss and Lomo, 1973). The extracellularly recorded population spike reflects the number of synchronously firing cells (Andersen et al., 1971). The relationship between the fEPSP and the population spike can thus be used to characterize the input/output (I/O) function of CA1 pyramidal neurons (Andersen et al., 1980). The first LTP studies noted that the potentiation of the population spike was often greater than could be accounted for by the fEPSP potentiation alone, and that in some cases, population spike potentiation occurred in the ab-

Received July 23, 2002; revised Sept. 26, 2002; accepted 0ct. 7, 2002

This research was supported by the EJLB Foundations, the National Science Foundation, and the National Institutes of Health (NIH). C.P.M. was supported by the NIH National Institute of General Medical Sciences training Grant GM08042, the Medical Scientist Training Program, the Aesculapians Fund of the University of California Los Angeles School of Medicine, and the Achievement Rewards for College Scientists Foundation. We thank Holly Carlisle, Uma Karmarkar, Victor Marder, Tom 0'Dell, and David Stanton for reading earlier versions of this manuscript.

Correspondence should be addressed to Dean V. Buonomano, Brain Research Institute, University of California, Los Angeles, Box 951761, Los Angeles, CA 90095. E-mail: dbuono@ucla.edu.

Copyright $\odot 2002$ Society for Neuroscience $\quad 0270-6474 / 02 / 220112-\bullet \$ 15.00 / 0$ sence of fEPSP potentiation (Bliss and Gardner-Medwin, 1973; Bliss and Lomo, 1973). This phenomenon was later termed EPSP-spike (E-S) potentiation (Andersen et al., 1980).

In this study, we have asked whether E-S potentiation also accompanies the changes in synaptic efficacy seen on a shorter time scale. The functional role of short-term plasticity is not well understood but has been theorized previously to contribute to temporal processing on a scale of tens to hundreds of milliseconds (Buonomano and Merzenich, 1995; Buonomano, 2000). Here we have used a paired-pulse paradigm in the range relevant to temporal information processing to produce short-term synaptic facilitation in area CA1. We found that although pairedpulse stimulation strengthens excitatory synapses, it does not translate into the predicted increase in action potential firing. In contrast to the E-S potentiation that accompanies LTP, E-S depression accompanies PPF at short interpulse intervals (IPIs) (50-100 msec). We propose that PPF leads to E-S depression through a relative increase in inhibition, and, in agreement with previous studies, that LTP is paralleled by a relative decrease in inhibition (Abraham et al., 1987; Chavez-Noriega et al., 1989; Lu et al., 2000). An understanding of these parallel changes occurring within excitatory-inhibitory disynaptic circuits will be fundamental to elucidating the functional effects of both short- and long-term EPSP plasticity.

\section{Materials and Methods}

Slice preparation. Experiments were performed on 400- $\mu$ m-thick transverse hippocampal slices from 17 - to 28 -d-old Sprague Dawley rats. The hippocampus was dissected out after halothane anesthesia and decapitation. Slices were cut from the dorsal hippocampus with a vibratome and submerged in oxygenated artificial CSF (ACSF) at room temperature. The ACSF was composed of (in mM): $119 \mathrm{NaCl}, 2.5 \mathrm{KCl}, 1.3 \mathrm{MgSO}_{4}, 1.0$ $\mathrm{NaH}_{2} \mathrm{PO}_{4}, 26.2 \mathrm{NaHCO}_{3}, 2.5 \mathrm{CaCl}_{2}$, and 10 glucose. For picrotoxin ex- 
periments, the CA3 region was removed with a knife cut. After an equilibration period of at least $1 \mathrm{hr}$, slices were transferred to a submerged recording chamber perfused at a rate of $2.5-3 \mathrm{ml} / \mathrm{min}$ and maintained at a temperature of $32 \pm 1^{\circ} \mathrm{C}$.

Field recordings. Microelectrodes were pulled from borosilicate glass [1.5 mm outer diameter (O.D.)/1.17 mm inner diameter (I.D.)] using a Flaming/Brown electrode puller (Sutter Instruments, Novato, CA). Two microelectrodes filled with $1 \mathrm{M} \mathrm{NaCl}(1-5 \mathrm{M} \Omega)$ were placed extracellularly in area CA1 to simultaneously record population spikes from stratum pyramidale and fEPSPs from stratum radiatum (see Fig. $1 A$ ). The microelectrodes were advanced to approximately the same depth in the slice and positioned along a line perpendicular to the cell body layer.

Sharp intracellular recordings. In some experiments, an intracellular micropipette was used in place of the population spike electrode. Because we hypothesized that the excitation-inhibition balance is of importance and because whole-cell recordings can considerably alter the IPSP reversal potential, we used sharp recordings. Micropipettes were pulled from borosilicate glass (1.2 mm O.D./0.68 mm I.D.) using a Flaming/Brown electrode puller (Sutter Instruments). Their resistance when filled with 3 M potassium acetate varied from 60 to $100 \mathrm{M} \Omega$. Cell penetrations were considered acceptable if they met the following criteria: resting potential below $-60 \mathrm{mV}$, input resistance of $\geq 30 \mathrm{M} \Omega$, and overshooting action potentials. Spike latency was calculated as the time from the stimulus artifact to the action potential peak. Hyperpolarization was calculated as the difference in base voltage $2-5 \mathrm{msec}$ before a first stimulus and 2-5 msec before a second stimulus arriving $50 \mathrm{msec}$ later (see Fig. 9B).

Electrical stimulation. For stimulation, platinum-iridium bipolar electrodes coated with platinum black (Frederick Haer Co., Bowdoinham, $\mathrm{ME}$ ) were placed in stratum radiatum, at the CA3-CA1 border and at the subicular end of CA1. The distance between the recording and stimulating sites was between 250 and $450 \mu \mathrm{m}$. Biphasic, constant current, 100 $\mu$ sec stimuli were delivered in pairs alternately to the two stratum radiatum inputs at $10-12 \mathrm{sec}$ intervals. Typically, paired pulses were given 50 msec apart. In the first set of experiments, a cycle of five interpulse intervals was used $(50,100,200,300$, and $400 \mathrm{msec})$. Baseline intensity was set below the threshold for population spikes, and stable baseline recordings were obtained for 10-20 min before basal E-S curves were measured.

For LTP experiments, baseline recordings were reestablished for $\sim 5$ min after completion of the basal E-S curves. LTP was induced in one pathway by high-frequency stimulation $(100 \mathrm{~Hz}$ for $1 \mathrm{sec}$, repeated two times at an interval of $20 \mathrm{sec}$ ), during which time the second pathway remained unstimulated. E-S curves were acquired at $13 \mathrm{~min}$ and again at 30 min after tetanus.

Pharmacology. For drug experiments, $100 \mu \mathrm{M}$ picrotoxin (PTX) or 15 $\mu \mathrm{M}$ flurazepam (FLZ) was dissolved in ACSF and bath applied after completion of the basal E-S curves. At least two additional E-S curves were then obtained in the presence of the drug. In a separate set of experiments (see Fig. 7A), the effects of FLZ were examined intracellularly on pharmacologically isolated evoked IPSPs. IPSPs were isolated by including $50 \mu \mathrm{M}$ APV and $10 \mu \mathrm{M}$ CNQX (dissolved in $1 \mathrm{ml}$ DMSO) in the ACSF. After successful cell penetration and a period of stable baseline recording, FLZ $(15 \mu \mathrm{M})$ was added to the APV/CNQX solution, and recordings were continued for an additional $30 \mathrm{~min}$. All drugs were acquired from Sigma (St. Louis, MO).

E-S curves. To obtain the data for the E-S curves, an ascending-descending series of $\sim 20-30$ stimulation intensities $(50-500 \mu \mathrm{A})$ was applied multiple times, covering a range of responses from subthreshold to supramaximal. E-S curves were constructed by plotting population spike amplitude versus fEPSP slope over the entire range of intensities sampled. The fEPSP slope was calculated as the absolute value of the maximal slope of the descending phase between 5 and $95 \%$ of the negative peak response. Population spike amplitude was calculated as the difference between the average of the two peak positivities and the peak negativity. Because the E-S curve for the second pulse reaches its upper asymptote at a lower intensity than the first pulse, in some experiments paired-pulse stimulation was switched to single pulse stimulation at the highest intensities. Only those experiments having stable baselines and stable E-S curves over multiple trials were included in the analysis.
Curve fitting was done using a custom-written MATLAB program. The program provided the best fit using a sigmoid with three free parameters: $S=S_{\max } /\left(1+\exp \left[\left(\mathrm{E}_{50}-E\right) / k\right]\right)$, where $S_{\max }$ is the asymptote, $\mathrm{E}_{50}$ is the fEPSP slope at $1 / 2 S_{\max }$, and $k$ reflects the slope of the sigmoid. To ensure that any differences in the curve fits were not caused by the range of values sampled, curves for pulse 2 were fit using only the data points falling below $5-10 \%$ of the maximum $y$-value obtained for pulse 1 . The extra points are indicated in the E-S plots by smaller markers.

Intracellular E-S curves. Intracellular E-S curves resemble the conventional E-S curves except that the output measure ( $y$-axis) was derived from the action potential firing probability of a single cell. Spikes were detected from sharp intracellular recordings as peak amplitudes exceeding a threshold value. Spike probability was calculated as the percentage of trials eliciting spikes at a given intensity. Thus, to plot the intracellular E-S curve, each stimulation setting of the I/O curve was applied for 10 consecutive sweeps. The $x$-value plotted was the average fEPSP slope over those 10 trials; the $y$-value plotted was the number of spikes. Note that the fEPSP at the threshold level of stimulation, defined as the intensity that produces five spikes in 10 trials, is the same as the $\mathrm{E}_{50}$ of the intracellular E-S curve.

Statistics. For statistical comparisons of E-S curves, we analyzed the percentage change in $\mathrm{E}_{50}$, a standard measure, plus two new measures: horizontal shift and vertical shift. These were defined as the percentage change from the control curve $\mathrm{E}_{50}$ to the horizontal and vertical intersections with the second curve (see Fig. 1C). Horizontal shift resembles $\mathrm{E}_{50}$ shift but is a more reliable and conservative measure when comparing two E-S curves that have different upper asymptotes. For the intracellular E-S curves, the upper asymptote is fixed at $100 \%$ cell firing probability (10 spikes/10 trials), so the standard $\mathrm{E}_{50}$ shift was used in these cases. Note that the $\mathrm{E}_{50}$ shift is equal to the horizontal shift for intracellular E-S curves. Statistical analyses of the shifts were done using two-tailed, onesample $t$ tests to determine significant differences from zero. Two-tailed paired $t$ tests were used for the flurazepam data.

\section{Results}

\section{Paired-pulse facilitation produces E-S depression}

We recorded simultaneous extracellular responses in stratum radiatum (fEPSPs) and stratum pyramidale (population spikes) from area CA1 of rat hippocampal slices while delivering paired stimuli over a series of intervals and intensities. A schematic diagram of the electrode arrangement is shown (Fig. $1 A$ ). The fEPSP slope provides a measure of the excitatory drive to the CA1 pyramidal neurons; the population spike amplitude reflects the number of pyramidal neurons producing action potentials. Both the fEPSPs and population spikes were facilitated at the $50 \mathrm{msec}$ IPI (Fig. 1A), with smaller degrees of facilitation visible at longer intervals (Fig. $1 B$ ). We compared the E-S curves generated by the two pulses at five IPIs by cycling through five IPIs at each intensity setting and plotting the resulting fEPSP-spike pairs (Fig. $1 C, D)$.

At the $50 \mathrm{msec}$ IPI (Fig. 1C), the E-S curve for pulse two was shifted to the right. This implies that the second pulse required a larger fEPSP to generate a population spike of a given size. Similarly, for a given fEPSP size, the second pulse generated a smaller population spike. In keeping with the established terminology, we refer to this rightward shift of the E-S curve as "E-S depression" (Andersen et al., 1980). The sample voltage traces (Fig. 1C) demonstrate that when matched for fEPSP slope, the second pulse produced less firing than the first. Thus, although both fEPSPs and population spikes were facilitated with a $50 \mathrm{msec}$ IPI, there was less firing in response to the second pulse than would have been expected for the increased synaptic drive. By $400 \mathrm{msec}$, the E-S curves for the two pulses coincided, as would independent, single pulses (Fig. 1D).

The summary statistics (Fig. 2) show that the E-S curve was significantly shifted rightward at $50 \mathrm{msec}\left(t_{13}=3.9 ; p<0.005\right)$ 

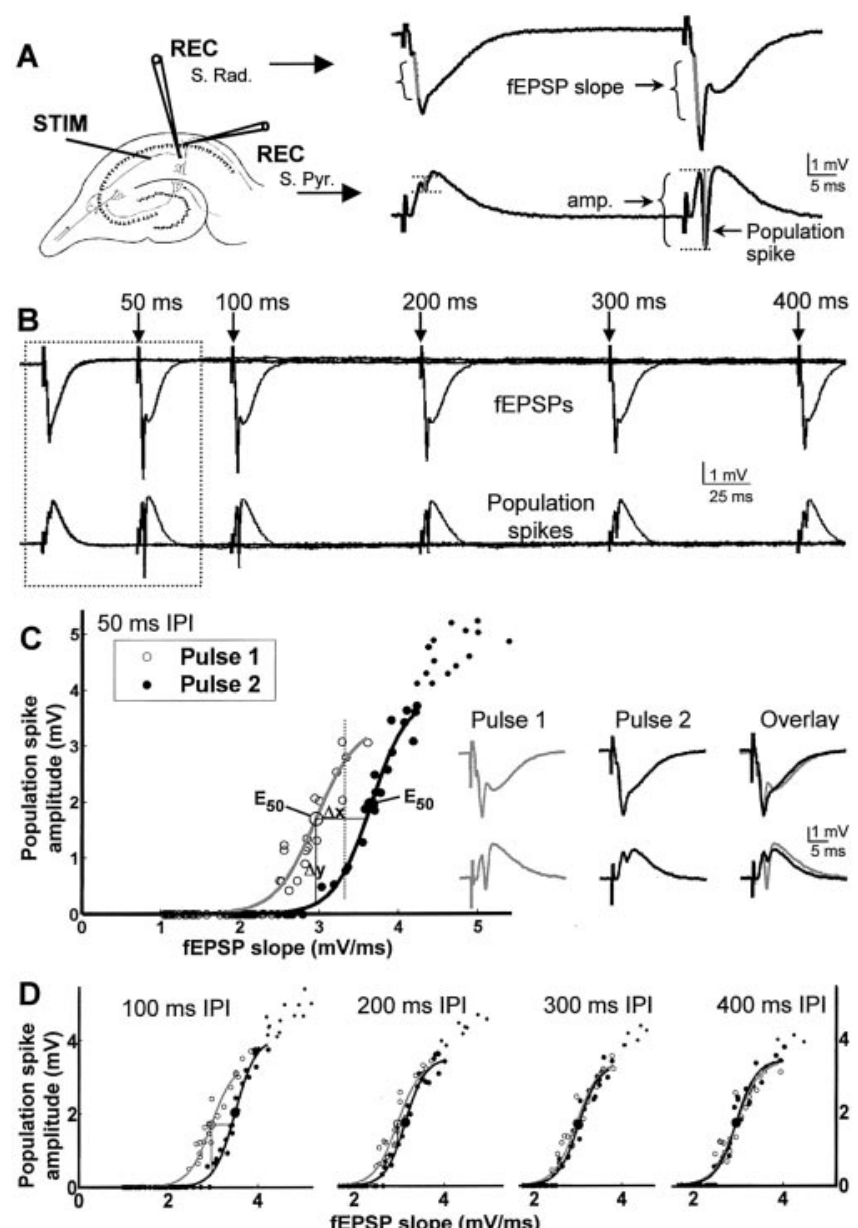

Figure 1. Field EPSPs produced by paired-pulse facilitation elicit less firing than single fEPSPs of the same size: E-S depression. A, Schematic diagram of stimulating and recording electrode positions in CA1, with sample Schaffer collateral-evoked extracellular responses to paired pulses with $50 \mathrm{msec}$ IPI. FEPSPs (top traces) were recorded from stratum radiatum (S. Rad.), the dendritic layer, and population spikes (bottom traces) were recorded from stratum pyramidale (S. Pyr.), the cell body layer. Gray lines indicate slope and amplitude measurements. $B$, Overlay of five consecutive sweeps of paired pulses at five IPIs using the same intensity. Both fEPSPs (top row) and population spikes (bottom row) showed PPF at all IPIs tested: 50, 100, 200, 300 , and $400 \mathrm{msec}$. Dotted outline indicates the traces shown in A. C, E-S curves for the $50 \mathrm{msec}$ data from the experiment shown above. E-S curves were plotted for pulse 1 (open circles, gray line) and pulse 2 (filled circles, black line) as the population spike amplitude versus fEPSP slope over a range of intensities. $A$ larger marker indicates the calculated $E_{50}$ for each curve. $\Delta x$ and $\Delta y$ are additional values used for the quantification of $\mathrm{E}-\mathrm{S}$ shifts, calculated as the distances from the $\mathrm{E}_{50}$ of the first curve to the horizontal $(\Delta x)$ and vertical $(\Delta y)$ intersections with the second curve. At the $50 \mathrm{msec} I \mathrm{PI}$, the E-S curve was shifted to the right, as reflected by positive values of $\Delta x$ and $\Delta \mathrm{E}_{50}$, and negative $\Delta y$. The sample voltage traces show that when matched for fEPSP slope (top row), pulse 2 (black traces) generated a smaller population spike (bottom row) than pulse 1 (gray traces). Traces correspond to the fEPSP slope indicated by the vertical dotted line. D, E-S curves for the 100, 200, 300, and 400 msec IPIs.

and at $100 \mathrm{msec}\left(t_{13}=3.1 ; p<0.01\right)$ and not at the longer intervals. We used three methods to quantify the E-S shifts (see Materials and Methods), and each yielded a similar result.

\section{Differential effects of PPF and LTP on cell firing}

We next compared the E-S shifts produced by PPF with those produced by LTP in the same slices. We used paired-pulse stimulation with a $50 \mathrm{msec}$ IPI and induced LTP by tetanic stimulation. The time course of a typical experiment is shown in Figure $3 A$. Note that the degree of PPF of the fEPSP slope before the tetanus is equal to the degree of LTP of the fEPSP slope measured
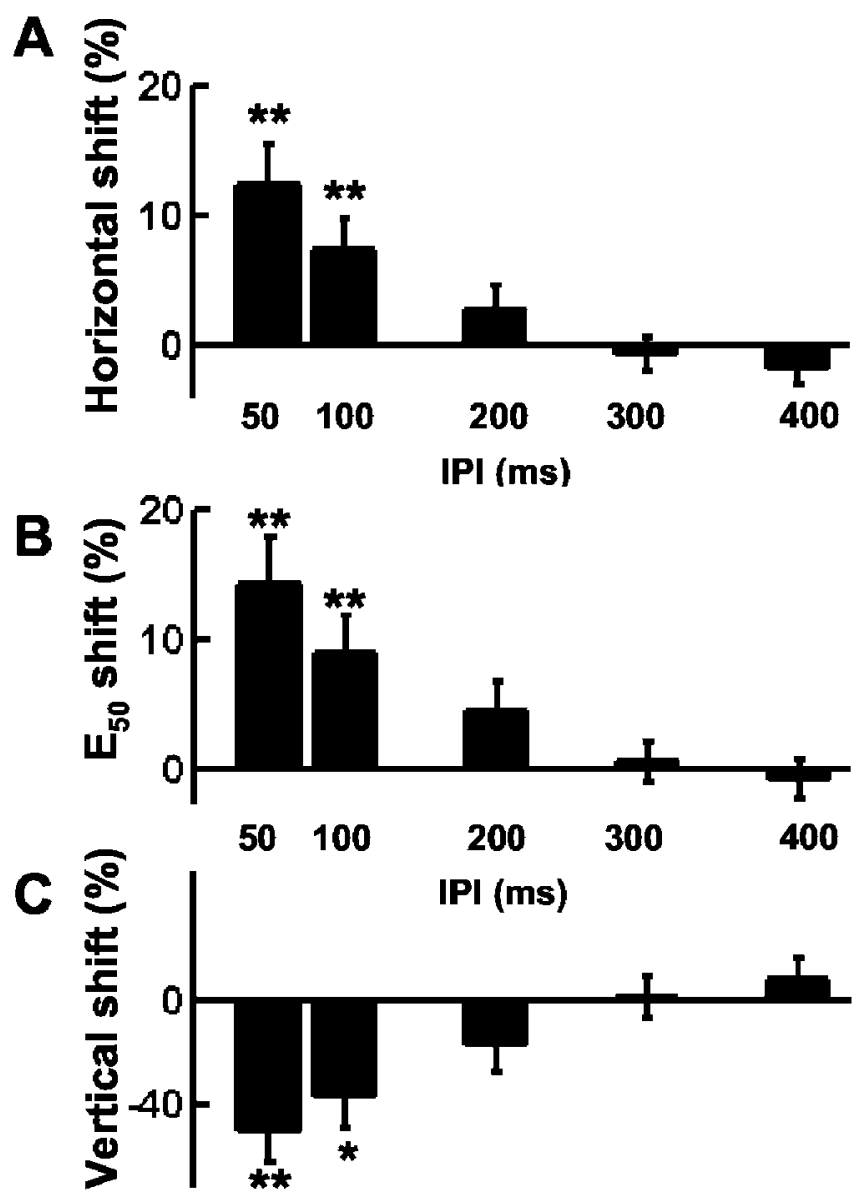

Figure 2. PPF shifts the E-S curve rightward at 50 and 100 msec. Quantification of E-S shifts from 14 experiments was done using three measures (Fig. 1C). $A$, The percentage change $\Delta x / x$ (horizontal shift), where $x$ is the $\mathrm{E}_{50}$ of the $\mathrm{E}-\mathrm{S}$ curve of the first pulse. $B$, The percentage change in $E_{50}$ from pulse 1 to pulse 2, or $\left[E_{50}(2)-E_{50}(1)\right] / E_{50}(1)$. C, The percentage change $\Delta y / y$ (vertical shift), where $y$ is the $y$-value at $E_{50}$ of the $E-S$ curve of the first pulse. Each measure revealed a significant rightward shift at 50 and $100 \mathrm{msec}$. Bars represent the mean shift; error bars represent SEM. Asterisks indicate a value significantly different from zero $\left({ }^{*} p<0.05\right.$; $\left.{ }^{* *} p<0.01\right)$.

30 min after the tetanus. Thus, one might have expected each of these fEPSPs to produce a similar amplitude population spike. The recordings from the cell body layer, however, show that only LTP produced a measurable population spike at this intensity (Fig. $3 A$, red traces) and that the same increase in synaptic strength produced by PPF did not result in cell firing (Fig. $3 A$, black traces).

By plotting the E-S curves using a range of intensities, we saw a differential effect of PPF and LTP on the entire I/O function (Fig. 3B). PPF shifted the E-S curve rightward, indicating E-S depression $\left(t_{13}=12 ; p<0.001\right)$, whereas LTP shifted the E-S curve leftward, indicating E-S potentiation $\left(t_{13}=-3.3 ; p<0.01\right)$ (for summary statistics, see Fig. 4 ). The traces in Figure $3 B$ further illustrate that inputs of the same synaptic strength can generate different outputs. The fEPSPs produced by LTP resulted in more firing, and the fEPSPs produced by PPF resulted in less firing, compared with fEPSPs of the same size produced under basal conditions.

To test whether E-S potentiation is pathway specific (Andersen et al., 1980; Abraham et al., 1985; Wathey et al., 1992; Jester et al., 1995), we performed experiments using a control, untetanized pathway (summary data) (Fig. 4). We found no sig- 

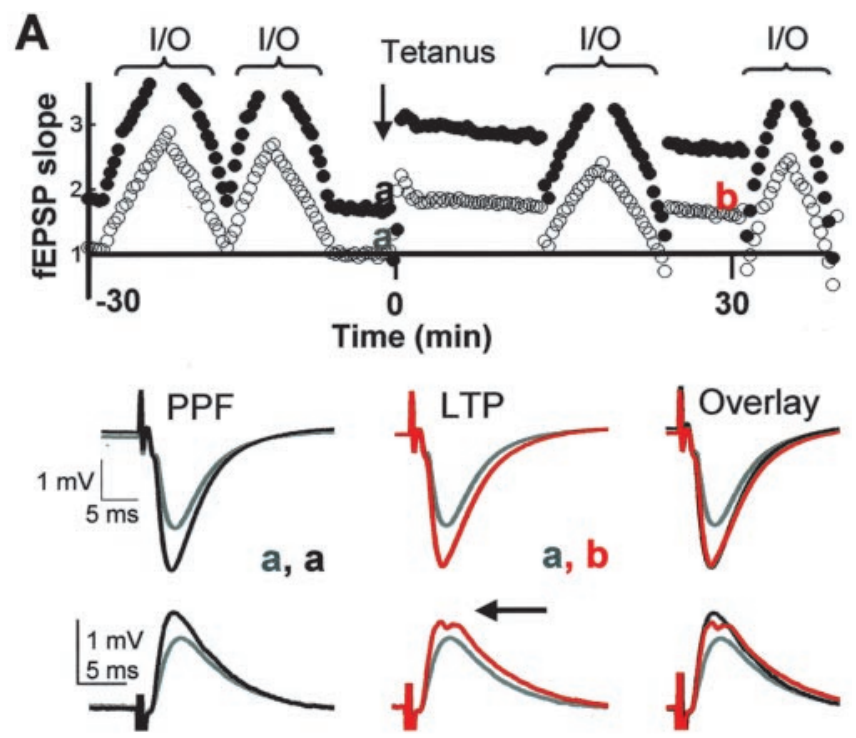

B
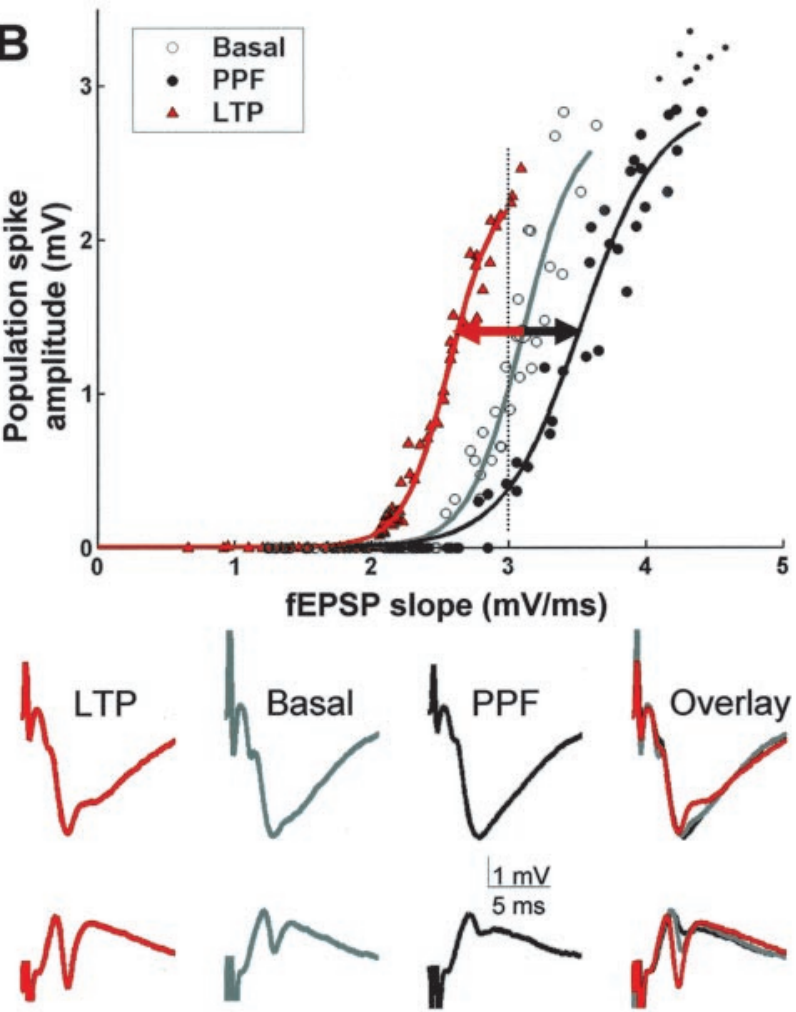

Figure 3. PPF and LTP produce opposite effects on EPSP-spike coupling. A, Time course of normalized fEPSP slopes for pulse $1(\bigcirc)$ and pulse $2(0)$ from a typical LTP experiment. Data were normalized to the baseline pulse 1 value, at time $a, 5$ min before LTP induction. Brackets indicate durations used for collecting $\mathrm{I} / 0$ data for the E-S curves. Note that the stimulus intensity was systematically changed in an ascending-descending manner. Paired-pulse stimulation was applied throughout with $50 \mathrm{msec} I \mathrm{PI}$, and LTP was induced by high-frequency tetanization $(100 \mathrm{~Hz}, 1 \mathrm{sec} \times 2)$ at time 0 . Note that the magnitude of PPF before the tetanus at time $a$ equals the magnitude of LTP $25-30 \mathrm{~min}$ after the tetanus at time $b$. Sample voltage traces are the average of 10 consecutive responses, for pulse 1 (gray) and pulse 2 (black) at time $a$, and for the first pulse 30 min after the tetanus at time $b$ (red). Note that PPF and LTP produced the same enhancement of synaptic strength (fEPSP, top traces), but only LTP resulted in action potential firing at this intensity (population spike, bottom traces). Arrow points to the small population spike produced at this intensity after LTP. B, E-S curves of the data shown in $A$ before and after tetanization. E-S curves were plotted for pulse 1 (open circles, gray line) and pulse 2 (filled circles, black line) before LTP, and for pulse 1 (red triangles, red line) after LTP. PPF and LTP shifted the E-S curve in opposite directions. Arrows indicate horizontal shifts. Sample voltage traces from all three conditions are shown. The fEPSP slopes were matched by plotting the data points corresponding to the vertical dotted line near $3 \mathrm{mV} / \mathrm{msec}$. For the same-sized fEPSP

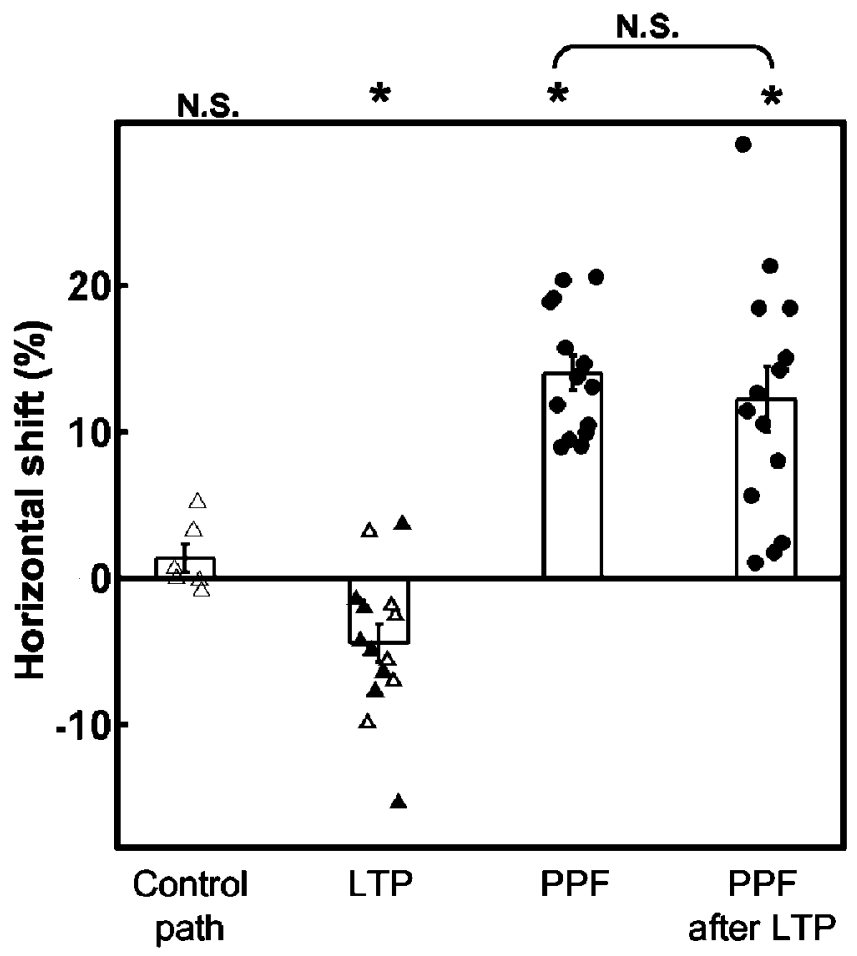

Figure 4. Summary of E-S shifts for PPF and LTP. Group data in which the E-S curves for PPF and LTP were measured in the same experiments. PPF shifted the E-S curve rightward $(p<$ $0.001 ; n=14)$, whereas LTP shifted the E-S curve leftward $(p<0.01 ; n=14)$. After LTP, PPF continued to shift the E-S curve rightward ( $p<0.001 ; n=14)$. In a control, untetanized pathway, there was no significant shift of the E-S curve $(p>0.2 ; n=6)$ measured before and after tetanization of the other pathway. Open triangles indicate the LTP experiments using a control pathway. Asterisk indicates a significant difference from zero $(p<0.01)$. N.S., Not significant.

nificant shift of the basal E-S curve in the control pathway $\left(t_{5}=\right.$ $1.4 ; p>0.2)$ measured before and after tetanization of the experimental path. This shows that E-S potentiation is pathway specific and indicates that for the unpotentiated inputs, the E-S curve is stable over the course of a typical experiment. We also examined whether the E-S depression produced by PPF was altered by LTP (summary data) (Fig. 4). After LTP, PPF continued to shift the E-S curve to the right $\left(t_{13}=5.6 ; p<0.001\right)$, and the E-S depression was not significantly different before and after LTP $\left(t_{13}=\right.$ $-1.0 ; p>0.3)$.

To test whether E-S depression is pathway specific, we performed experiments using two pathways. Pathway one (P1) was held at a fixed intensity, whereas pathway two (P2) was varied over a range of intensities as described above (see Materials and Methods). Paired pulses $50 \mathrm{msec}$ apart were delivered homosynaptically (P2-P2) and heterosynaptically (P1-P2) in alternation, and the responses in $\mathrm{P} 2$ were analyzed for E-S shifts (Fig. 5A). We found significant E-S depression in P2 as a result of both homosynaptic $\left(p<0.005 ; t_{4}=7.57\right)$ and heterosynaptic $(p<0.001$; $t_{4}=9.2$ ) stimulation (Fig. $5 B$ ). This shows that E-S depression is not pathway specific.

$\leftarrow$

slope (top traces), LTP (red) resulted in a larger population spike (bottom traces), and PPF (black) resulted in a smaller population spike, compared with the basal (gray) population spike produced by increasing the intensity alone. 

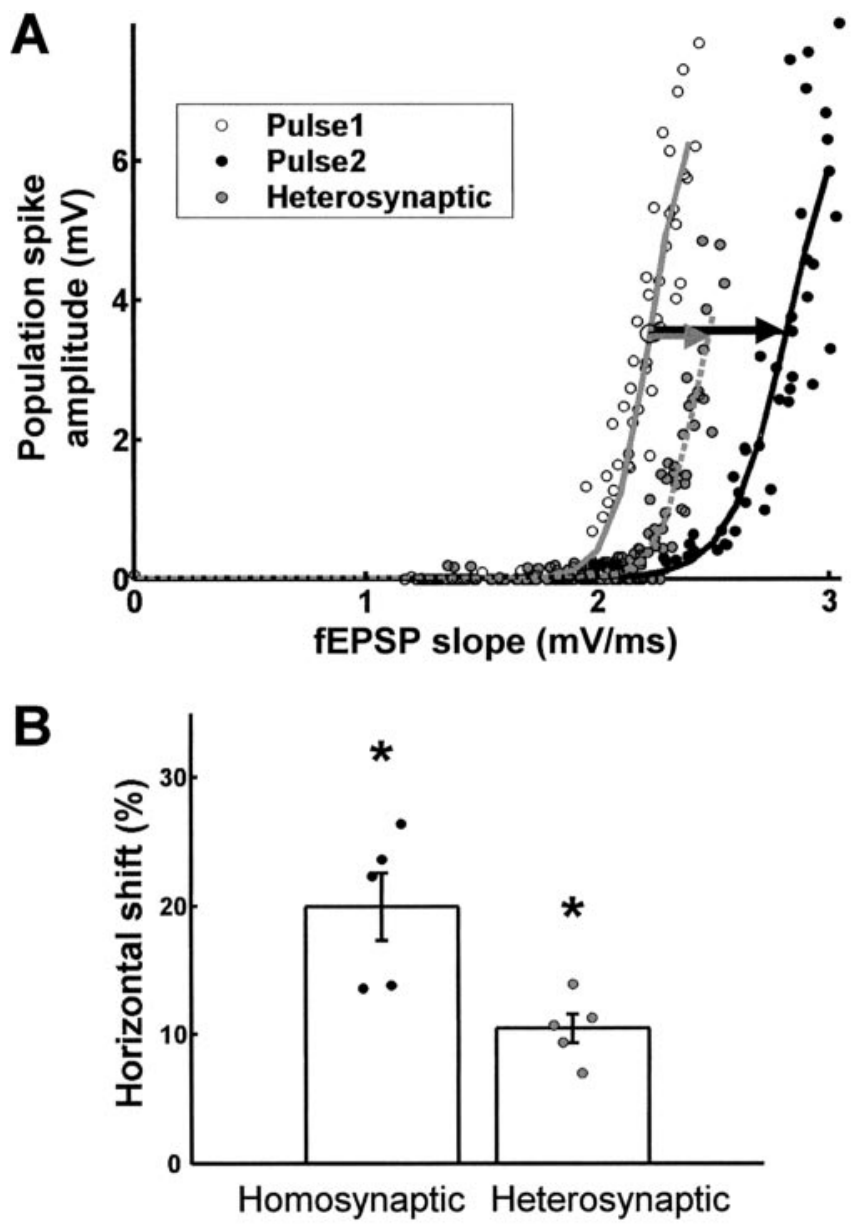

Figure 5. E-S depression is not pathway specific. A, E-S curves from a sample experiment in which paired stimuli 50 msec apart were delivered homosynaptically (P2-P2) and heterosynaptically (P1-P2). The E-S curves shown correspond to responses in P2 as follows: Pulse 1, open circles, gray line; Pulse 2, black filled circles, black line; the heterosynaptic pulse (P2 preceded by P1), gray filled circles, gray dashed line. Note that both homosynaptic and heterosynaptic stimulation shifted the E-S curve rightward. B, Summary data from five experiments; individual experiments are indicated by filled circles. There is a significant mean rightward shift of the $\mathrm{E}-\mathrm{S}$ curve in both the homosynaptic and heterosynaptic conditions (bars represent the mean; error bars represent SEM; $\left.{ }^{*} p<0.005\right)$.

\section{Blocking $\mathrm{GABA}_{\mathrm{A}}$ receptors blocks PPF-induced}

\section{E-S depression}

The E-S depression that we observed during PPF could rely, in principle, on the inhibitory branch of the local circuit (Fig. 6D) or on a cellular mechanism such as spike accommodation or a slow afterhyperpolarization. Furthermore, an inhibitory role could operate via $\mathrm{GABA}_{\mathrm{A}}$ receptor $\left(\mathrm{GABA}_{\mathrm{A}} \mathrm{R}\right)$-mediated fast IPSPs or $\mathrm{GABA}_{B} \mathrm{R}$-mediated presynaptic or postsynaptic mechanisms. As already shown (Fig. 2), the maximum E-S shifts occurred with the 50-100 msec IPIs, and no detectable shifts occurred with the 200-300 msec IPIs. Because it is well established that presynaptic and postsynaptic $\mathrm{GABA}_{\mathrm{B}} \mathrm{R}$ effects peak at $200-$ 300 msec (Fukuda et al., 1993; Buonomano and Merzenich, 1998), it is unlikely that $\mathrm{GABA}_{\mathrm{B}} \mathrm{R}$-mediated mechanisms are contributing to E-S depression. We therefore used PTX, a GABA ${ }_{A} R$ antagonist, to test the hypothesis that E-S depression relies on network mechanisms.

We repeated the above experiments while blocking the GABA $_{A}$ Rs with $100 \mu \mathrm{M}$ PTX (Fig. 6A). To maximize the E-S depression in the control condition, we used a 50 msec IPI. We
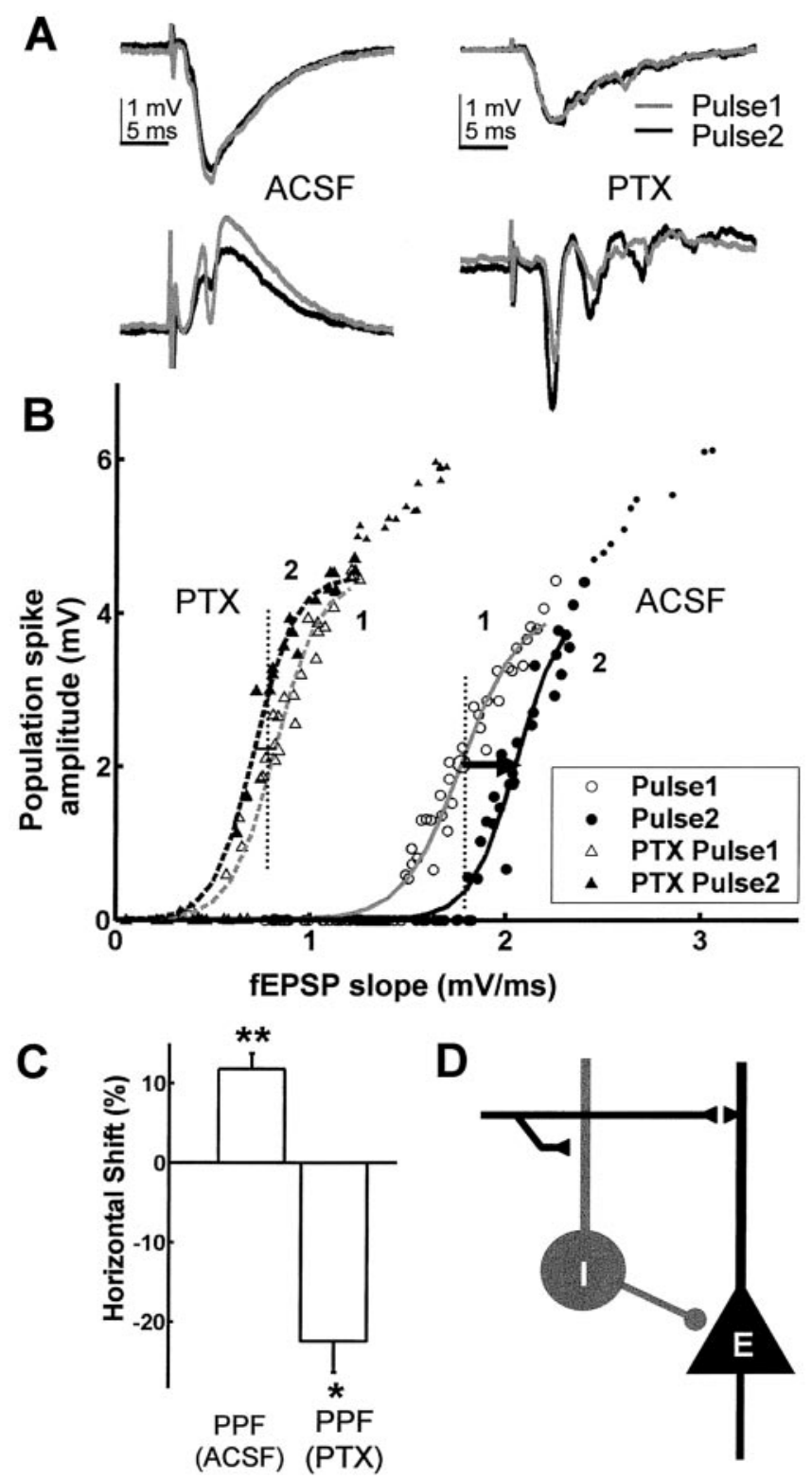

Figure 6. Picrotoxin blocks PPF-induced E-S depression. $A$, Sample voltage traces in control conditions (ACSF, left) and picrotoxin (PTX, $100 \mu \mathrm{m}$, right). Gray traces are pulse 1 fEPSP (top row) and population spike (bottom row); black traces correspond to pulse 2 (50 msec IPI), matched to the same fEPSP slope as pulse 1 (see vertical dotted lines in $B$ ). Note the E-S depression of pulse 2 in ACSF but not in PTX. B, E-S curves obtained for the experiment shown in $A$. Before PTX, PPF shifted the E-S curve to the right (gray line to black line). Consistent with the circuits shown in D, PTX itself produced a dramatic shift in the E-S curve leftward (gray line to gray dashed line) and prevented any further rightward shift by PPF (gray dashed line to black dashed line). C, Average data from four experiments shows that the PPF-induced right shift requires intact inhibition. In normal ACSF, PPF shifted the E-S curve to the right. In PTX, PPF shifted the E-S curve to the left. Bars represent the mean; error bars represent SEM; asterisks indicate a significant difference from zero $\left({ }^{*} p<0.05\right.$; $\left.{ }^{* *} p<0.01\right)$. D, Schematic diagram of disynaptic circuit composed of an excitatory and inhibitory neuron arranged in a feedforward manner. The circuit is composed of three different synapses: Input $\rightarrow$ Ex (Schaffer collateral to pyramidal neuron), Input $\rightarrow$ Inh (Schaffer collateral to inhibitory interneuron), and Inh $\rightarrow$ Ex (inhibitory to pyramidal neuron). A relative increase in inhibition would shift the E-S curve rightward, whereas a relative decrease in inhibition would shift the E-S curve leftward.

first obtained E-S curves in the absence and then in the presence of PTX (Fig. $6 B$ ) (in these experiments, the CA3 region was removed; see Materials and Methods). In agreement with previous studies of E-S potentiation, bath application of the $\mathrm{GABA}_{\mathrm{A}} \mathrm{R}$ an- 


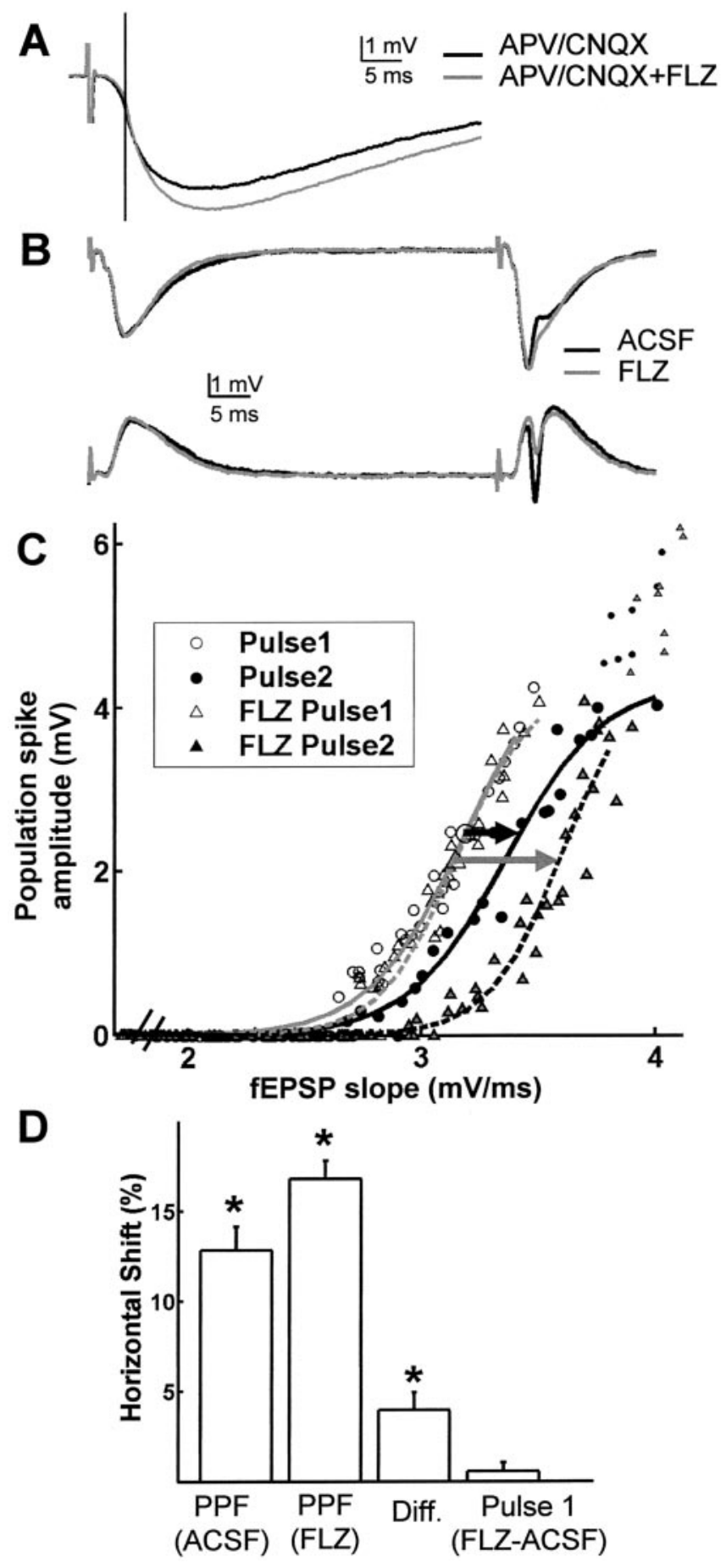

Figure 7. Benzodiazepine enhances PPF-induced E-S depression. A, Sample intracellular recording of pharmacologically isolated IPSPs (10 $\mu \mathrm{m}$ CNQX and $50 \mu \mathrm{MAPV}$ ) before (black trace) and after (gray trace) addition of $15 \mu \mathrm{m}$ flurazepam (FLZ). Traces are the average of 20 sweeps. Vertical line is drawn to indicate the mean action potential latency of pulse 1 ( $5.1 \mathrm{msec}$ ) recorded in pyramidal cells under intact pharmacological conditions in a separate set of experiments (Figs. 8,9). Note that the enhancement of the IPSP by FLZ primarily changes the later phases of the IPSP relative to the spike latency for pulse 1.B, Sample field recordings from another slice in normal ACSF (blacktraces) and after addition of $15 \mu \mathrm{m}$ FLZ (gray traces). Top row, fEPSPs; bottom row, population spikes. FLZ did not change baseline fEPSP slope or PPF of the fEPSP slope; however, the second fEPSP elicited less firing (a smaller population spike) in the presence of FLZ. C, E-S curves from the experiment displayed in B. FLZ produced no change in the basal E-S curve, Pulse 1 (open circles, gray line), compared with FLZ, Pulse 1 (open triangles, gray dashed line); however, PPF in FLZ resulted in a larger rightward shift (gray arrow) than in ACSF (black arrow). $D$, Summary data of horizontal shifts produced by PPF in normal ACSF and in FLZ in the same experiments. The mean difference (Diff.) indicates a significantly greater rightward shift in FLZ tagonist itself caused a large leftward shift of the E-S curve (Abraham et al., 1987; Chavez-Noriega et al., 1989; Lu et al., 2000). Nevertheless, although in four of four experiments PPF elicited the usual rightward shift before application of PTX $\left(t_{3}=6.2 ; p<\right.$ 0.01 ), no rightward shifts occurred in the presence of PTX. In fact, PTX appears to have reversed the effect of PPF on the E-S curve from a rightward to a leftward shift $\left(t_{3}=-5.7 ; p<0.05\right)$ (Fig. 6C). This implies that intrinsic conductances are not responsible for the rightward shift, and indeed that intrinsic membrane properties may favor E-S potentiation rather than E-S depression.

These experiments suggest that $\mathrm{GABA}_{\mathrm{A}} \mathrm{R}$-mediated inhibition is necessary for PPF-induced E-S depression to occur. However, because PTX itself produced a significant shift of the first pulse E-S curve, the absence of a rightward shift could be caused, in part, by differences in initial conditions. To address this issue, we next examined the role of $\mathrm{GABA}_{\mathrm{A}} \mathrm{R}$-mediated inhibition by using a benzodiazepine agonist.

\section{Benzodiazepine enhances PPF-induced E-S depression} without shifting the basal E-S curve

The experiments above suggest that $\mathrm{GABA}_{\mathrm{A}}$ ergic processes contribute to the E-S depression accompanying PPF. One possibility is that inhibition produced by the first pulse counteracts the EPSP facilitation at the second pulse. This hypothesis predicts that increasing the duration of the first IPSP should further enhance the magnitude of the right shift observed during PPF. To test this hypothesis we used a benzodiazepine agonist, which enhances the duration of fast IPSPs onto pyramidal neurons (Mody et al., 1994) (Fig. 7A). Although we have focused on the benzodiazepine effects on pyramidal cells, it should be noted that similar effects might occur on inhibitory neurons (Hajos et al., 2000; Patenaude et al., 2001).

FLZ $(15 \mu \mathrm{M})$ did not change the baseline slope of the first fEPSP or the degree of PPF (Fig. 7B) (Tuff et al., 1983). Subtle changes in fEPSP waveform shape were observed, such as a narrower shape consistent with enhancement of the IPSP. In the presence of FLZ, although PPF was the same, the second pulse elicited less firing (a smaller population spike) than was observed previously in normal ACSF (Fig. 7B) (Tuff et al., 1983). This diminished firing on the second pulse accounts for the significant increase in the rightward shift of the E-S curve seen after addition of FLZ (Fig. $7 C, D)\left(t_{13}=3.9 ; p<0.005\right)$. Note that in contrast to PTX (Fig. $6 B$ ), FLZ did not shift the Pulse 1 E-S curve (Fig. 7C,D) $\left(t_{13}=1.09 ; p=0.29\right)$. Because FLZ enhanced the rightward shift but did not alter the E-S curve of the first pulse, these results indicate that $\mathrm{GABA}_{\mathrm{A}}$ ergic processes play a role in $\mathrm{PPF}$-induced E-S depression. Specifically, these data support the hypothesis that E-S depression depends on the strength of the first IPSP.

PPF-induced E-S depression in single pyramidal neurons

To confirm that PPF-induced E-S depression is observed at the single-cell level, and to further examine the underlying mechanisms, we performed intracellular experiments with sharp electrodes. We constructed intracellular E-S curves using action potential firing probability in place of population spike amplitude (see Materials and Methods). In general, compared with conven-

$\leftarrow$

compared with normal ACSF $(p<0.005 ; n=14)$. No change was found in the Pulse $1 \mathrm{E}-\mathrm{S}$ curve before and after FLZ $(p>0.25 ; n=14)$. Bars represent the mean; error bars represent SEM; asterisk represents a significant difference from zero $(p<0.005)$. 


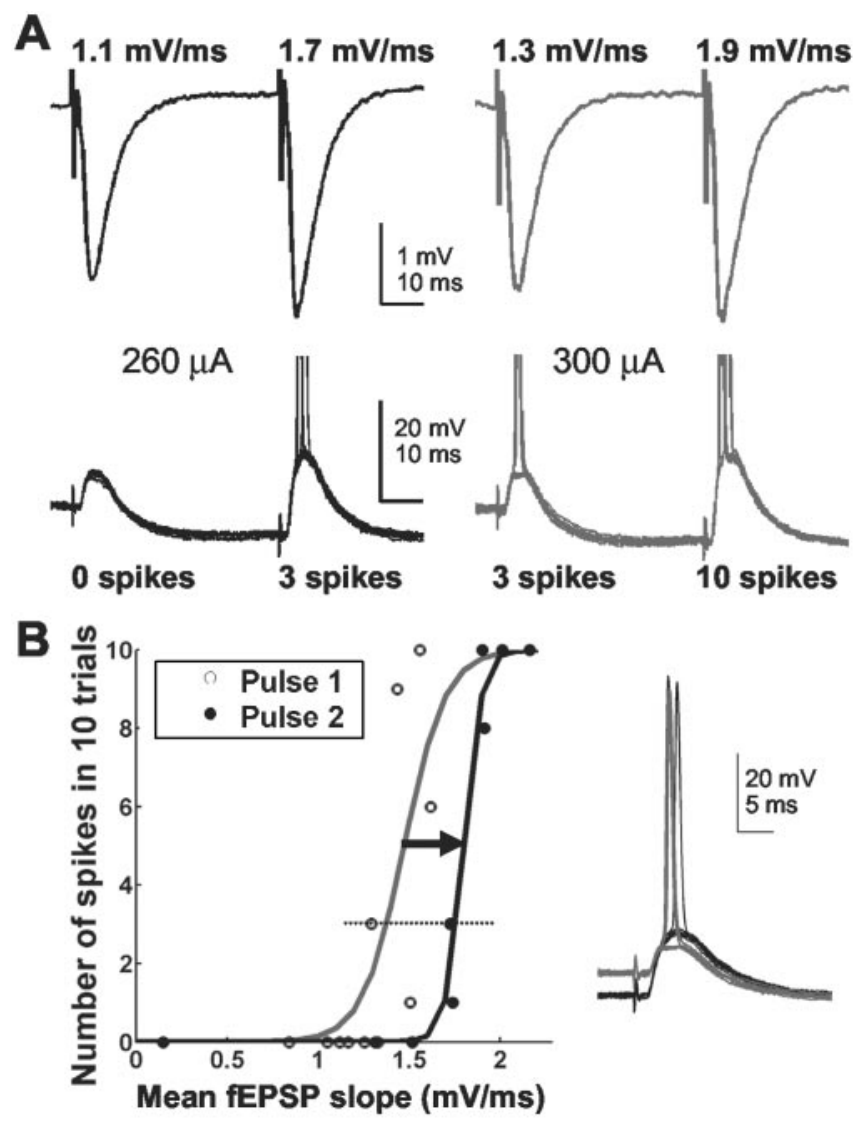

Figure 8. Intracellular demonstration of E-S depression. $A$, Sample voltage traces from a representative experiment near threshold. Top row, fEPSPs; average of 10 consecutive responses to paired stimuli ( $50 \mathrm{msec}$ IPI) at $260 \mu \mathrm{A}$ (black) and then at $300 \mu \mathrm{A}$ (gray). Bottom row, The corresponding 10 intracellular recordings at the two intensities, showing both spikefree and spike-containing EPSP-IPSP sequences. Note that the first intensity produced 3 of 10 spikes on pulse 2, and the second intensity produced 3 of 10 spikes on pulse 1, but the corresponding fEPSPs show that pulse 2 required a larger fEPSP to reach the same spike probability. $B$, Intracellular E-S curves for pulse 1 (open circles, gray line) and pulse 2 (filled circles, black line) from the same experiment shown in $A$. Note that the pulse $2 \mathrm{E}-\mathrm{S}$ curve is shifted to the right (arrow indicates $\mathrm{E}_{50}$ shift). The dotted line passes through the points corresponding to the threshold traces shown in $A$. The intracellular traces at threshold are redrawn to the right superimposed, to show that the second pulse reaches threshold on a larger EPSP that originates from a more hyperpolarized potential.

tional E-S curves, the upper asymptotes of intracellular E-S curves (defined as 10 spikes/10 trials) were reached using less intense stimulation and smaller fEPSPs. Figure 8 shows a representative intracellular example of PPF-induced E-S depression. Some cells, on the other hand, exhibited E-S potentiation (Fig. $9 A)$. As with the field E-S curves, there was a mean rightward shift (Fig. 9A) $\left(t_{49}=3.19 ; p<0.005\right)$ of $\sim 13.2 \%$, approximately the same percentage shift as determined previously using field recordings (Figs. 2, 4).

To confirm that E-S depression is caused by inhibition, we analyzed two additional measures that reflected IPSP strength: the hyperpolarization from resting potential at $45-48 \mathrm{msec}$ after a stimulus (just before pulse 2) (Fig. 9B) and the EPSP decay time constant $\left(\tau_{\mathrm{D}}\right)$ (data not shown). To quantify these measures for each experiment, we averaged over the 10 sweeps closest to threshold intensity for pulse 2 (Fig. 9B). We found that the magnitude of E-S depression in single cells significantly correlated with the magnitude of the hyperpolarization (Fig. 9C) $(r=$ $\left.-0.43 ; t_{48}=-3.31 ; p<0.005\right)$ as well as (inversely) with the $\tau_{\mathrm{D}}$
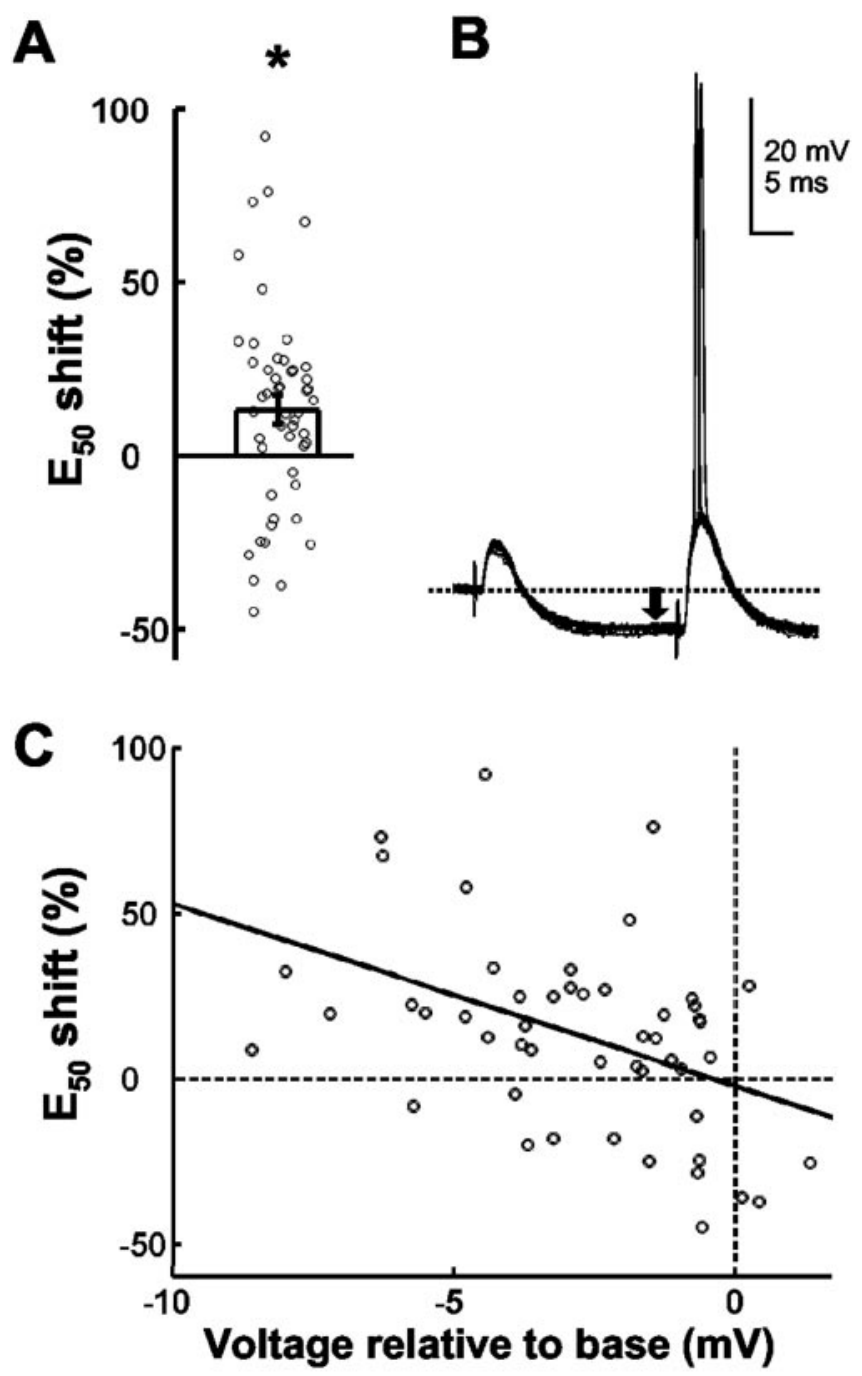

Figure 9. Intracellular E-S depression correlates with inhibition. A, Summary of intracellular $\mathrm{E}-\mathrm{S}$ shifts. Open circles represent $\mathrm{E}_{50}$ shift in 50 experiments ( 28 cells). Bar represents the mean; error bars represent \pm SEM. There was a mean rightward shift of the E-S curve; asterisk indicates a significant difference from zero $(p<0.005)$. B, Traces at threshold for pulse 2 (same cell as Fig. $8 A$ ). Arrow indicates hyperpolarization from base (dotted line). C, Significant correlation ( $r=$ $-0.43 ; p<0.005$ ) between $\mathrm{E}_{50}$ shifts in single cells and the magnitude of hyperpolarization preceding the second pulse.

of the first EPSP $\left(r=-0.42 ; t_{48}=-3.24 ; p<0.005\right)$. This supports the conclusion that E-S depression results from inhibition of cell firing on the second facilitated EPSP, because of the influence of the first IPSP.

\section{Discussion}

E-S coupling provides a measure of the I/O function of a population of cells. It is well known that LTP can enhance the I/O function of pyramidal neurons through the process of E-S potentiation (Andersen et al., 1980; Abraham et al., 1987; ChavezNoriega et al., 1989; Leung and $\mathrm{Au}, 1994$; Lu et al., 2000). The intracellular correlate of E-S potentiation, a decreased EPSP slope at action potential firing threshold, has also been established after LTP (Andersen et al., 1980; Abraham et al., 1987). In addition, it has been reported that short-term potentiation induced by highfrequency stimulation does not produce a change in the E-S curve (Abraham et al., 1985). Similarly, a previous study examining paired pulses also reported no shift or a leftward shift (Leung and 
$\mathrm{Fu}, 1994)$. However, both of these studies relied on somatic field responses only, and thus could not provide an accurate measure of the I/O function, because EPSPs recorded in the cell layer are masked by a strong feedforward inhibitory component (Pouille and Scanziani, 2001). Here we show for the first time that PPF, which can produce the same degree of fEPSP potentiation as LTP, produces a consistent depression of the pyramidal cell I/O function. This E-S depression manifests at the both the population and single-cell levels.

The PPF-induced E-S depression observed here is to some extent similar to paired-pulse suppression of population spikes described in vivo in the dentate gyrus (Tuff et al., 1983). There are notable distinctions, however. A triphasic pattern is seen in the dentate gyrus, with depression of population spikes at short (20-30 msec) and long (150-500 msec) IPIs, presumably mediated by GABAergic inhibition, and facilitation at intermediate IPIs (50-90 msec) (Tuff et al., 1983; Burdette and Gilbert, 1995). More importantly, it has been shown that the early depression of population spikes is predicted by depression of the fEPSP slopes (Burdette and Gilbert, 1995, their Fig. 2B). In contrast, we have shown a reliable facilitation of fEPSPs and population spikes, with simultaneous EPSP-spike depression.

\section{Mechanism of PPF-induced EPSP-spike depression}

E-S depression could rely on cellular or network mechanisms. The rightward shift in E-S depression signifies that in comparison to the first pulse, the second pulse requires a larger EPSP to produce an action potential. On the cellular side, this E-S depression could result from decreased excitability of the cell, as a consequence of the afterhyperpolarization, for example. On the network side, E-S depression could rely on relative changes in the balance of excitation and inhibition. The PTX experiments (Fig. 6) imply strongly that normal PPF-induced E-S depression relies on intact inhibitory pathways using $\mathrm{GABA}_{\mathrm{A}} \mathrm{Rs}$. There are two major sources of inhibition of CA1 pyramidal neurons: feedforward and feedback (Buzsaki, 1984; Freund and Buzsaki, 1996). Although both are likely to contribute to E-S depression, feedforward inhibition is more likely to play a principal role. This is because feedback inhibition relies on the firing of the pyramidal neurons (Buzsaki, 1984), and E-S curves for pulse 2 were usually generated at intensities below population spike threshold for pulse 1. Furthermore, single cells were found to reach threshold for pulse 2 without firing on pulse 1 (Fig. 9B). Alternatively, feedforward inhibition is activated by these low, subthreshold stimulation intensities (Buzsaki, 1984; Karnup and Stelzer, 1999) and is likely to be the major contributor to the E-S depression observed here.

E-S depression could occur as a result of PPF in the disynaptic inhibitory branch of the circuit (Fig. 6D) or temporal overlap of the EPSP of the second pulse with the residual fast IPSP of the first pulse (Fig. 9B). Because it is believed that paired-pulse depression $(\mathrm{PPD})$ predominates at the inhibitory-to-excitatory $(\mathrm{Inh} \rightarrow \mathrm{Ex})$ synapses in the hippocampus (Davies et al., 1990; Yoon and Rothman, 1991; Mott et al., 1993), the first explanation seems unlikely. We have confirmed in our experiments on pharmacologically isolated IPSPs that paired-pulse stimulation with a 50 msec IPI produces marked PPD of the monosynaptic IPSP (data not shown). Evidence from paired recordings, however, suggests that both PPF and PPD can occur at the Inh $\rightarrow$ Ex synapses, as well as at pyramidal cell inputs onto interneurons (Ali and Thomson, 1998; Ali et al., 1998; Jiang et al., 2000; Maccaferri et al., 2000). It therefore remains uncertain whether paired-pulse modulation in the disynaptic pathway could produce a net increase in inhibition evoked on the second pulse, but this is unlikely, given the strong evidence for PPD of IPSPs.

We have used the benzodiazepine agonist FLZ to test the possibility that PPF causes E-S depression by temporal overlap of the second EPSP with the residual fast IPSP. As a class, benzodiazepines enhance the frequency of bursting of $\mathrm{GABA}_{\mathrm{A}} \mathrm{R}$-mediated $\mathrm{Cl}^{-}$channels (MacDonald and Meldrum, 1989), resulting in prolonged GABAergic currents and extended IPSPs (Otis and Mody, 1992; Mody et al., 1994) (Fig. 7A). The temporal summation explanation for E-S depression predicts that enhancement of the residual IPSP by FLZ could profoundly affect action potential firing on the second pulse without affecting firing on the first pulse. Indeed, as shown in Figure 7, FLZ significantly increased the rightward shift in response to PPF, without significantly shifting the basal E-S curve. These data, along with the intracellular data showing a correlation between E-S depression and the hyperpolarization preceding the second stimulus (Fig. 9C), strongly support the hypothesis that the temporal overlap of the second EPSP with the first IPSP causes E-S depression.

Supportive evidence is also provided by the data showing that E-S depression is not pathway specific (Fig. 5). Note that although the IPSP hypothesis predicts a heterosynaptic effect, it does not predict whether the magnitude of the effect should be complete or partial. This is because (1) there is no a priori way to equate the degree of inhibition activated by each pathway, and (2) the stimulation intensity used for pathway one was fixed, whereas the stimulation intensity for pathway two was varied. Therefore, the magnitude of the shift in the heterosynaptic case will not be comparable with the magnitude of the shift in the homosynaptic case. Although these data are potentially confounded, because it is difficult to exclude the possibility of overlap between the pathways at high intensities, the results suggest that E-S depression is heterosynaptic, consistent with the IPSP hypothesis.

\section{Mechanism of LTP-induced EPSP-spike potentiation}

E-S potentiation produced by LTP could be caused by long-term changes in cell excitability (Haas and Rose, 1982; Abraham et al., 1985; Taube and Schwartzkroin, 1988; Wathey et al., 1992; Jester et al., 1995) or by increases in the ratio of excitation to inhibition (Wilson et al., 1981; Abraham et al., 1987; Chavez-Noriega et al., 1989; Lu et al., 2000). Andersen et al. (1980) argued that E-S potentiation could not be explained by increased intrinsic excitability of pyramidal cells, because an untetanized control path failed to elicit the effect. A relative loss of inhibition resulting from greater LTP onto pyramidal cells (Input $\rightarrow \mathrm{Ex}$ ) compared with interneurons (Input $\rightarrow$ Inh) has been proposed as a mechanism for E-S potentiation (Wilson et al., 1981; Abraham et al., 1987). Additionally, a molecular mechanism has been described involving LTD of the $\mathrm{GABA}_{\mathrm{A}} \mathrm{R}$-mediated IPSP that occurs in parallel with LTP of the EPSP and requires activation of NMDA receptors and calcineurin ( $\mathrm{Lu}$ et al., 2000). Consistent with either of these mechanisms is the finding that E-S potentiation is blocked by $\mathrm{GABA}_{\mathrm{A}} \mathrm{R}$ antagonists such as PTX or bicuculline (Abraham et al., 1987; Chavez-Noriega et al., 1989; Lu et al., 2000).

A fundamental issue is whether the protocol that induces LTP of the Input $\rightarrow$ Ex synapses in CA1 also produces long-term plasticity of the Input $\rightarrow$ Inh or Inh $\rightarrow$ Ex synapses. E-S potentiation could be produced by concomitant LTD of either of these synapses. Tetanus-induced Input $\rightarrow$ Inh LTP (Stelzer et al., 1994; Cowan et al., 1998) and LTD (McMahon and Kauer, 1997) have been observed. Similarly, both LTP (Xie et al., 1995) and LTD (Lu 
et al., 2000) have been reported at the Inh $\rightarrow$ Ex synapses. This variability may reflect differences in the inhibitory cell types being examined. For instance, in CA1, stratum oriens interneurons undergo LTP, either directly (Perez et al., 2001) or propagated passively from potentiated pyramidal neurons (Ouardouz and Lacaille, 1995; Maccaferri and McBain, 1996), whereas stratum radiatum interneurons undergo direct, tetanus-induced LTD (McMahon and Kauer, 1997).

Although our studies did not set out to examine the mechanisms underlying LTP-induced E-S potentiation, our results showing that E-S potentiation is pathway specific are consistent with changes in inhibition (Abraham et al., 1987; ChavezNoriega et al., 1989; Lu et al., 2000).

\section{Computational implications}

Changes in synaptic strength produced by short-term or longterm plasticity play an important role in neural computation. The computational consequences of LTP have long been thought to underlie learning and memory. Specifically, increases in synaptic strength translate into increases in neuronal firing, which in turn may facilitate the generation of a particular behavior. As discussed above, neuronal firing depends not only on the strength of EPSPs, but also on the net balance between excitation and inhibition (Buzsaki, 1984; Pouille and Scanziani, 2001). Although LTP of EPSPs has not generally been studied in the context of parallel changes in inhibition, previous results (Bliss and Gardner-Medwin, 1973; Bliss and Lomo, 1973; Andersen et al., 1980; Abraham et al., 1987; Kairiss et al., 1987; Chavez-Noriega et al., 1989; Lu et al., 2000) and the data shown here indicate that LTP does translate into increased cell firing. It remains to be shown, however, whether the shift in E-S coupling during LTP occurs under physiological induction of LTP, such as pairinginduced associative LTP in single pyramidal cells.

The computational role of short-term forms of plasticity such as PPF and PPD has been less clear. PPF has been proposed to be involved in temporal processing (Buonomano and Merzenich, 1995; Buonomano, 2000) and "on-line" modulation of neural circuits (Fisher et al., 1997). PPD has been proposed to contribute to synchrony generation (Tsodyks et al., 2000) and gain control (Abbott et al., 1997), maintaining the stability of cortical circuits by keeping positive feedback in check (Galarreta and Hestrin, 1998). We have suggested previously that PPF coupled with dynamic changes in excitatory-inhibitory balance in disynaptic circuits can lead to the generation of interval selective neurons (Buonomano, 2000). We define a disynaptic circuit as being composed of a single projecting excitatory and local inhibitory neuron arranged in a feedforward manner (Fig. 6D). Within this circuit there are three different synapses that can potentially undergo plasticity: Input $\rightarrow$ Ex, Input $\rightarrow$ Inh, and Inh $\rightarrow$ Ex. Theoretical work has shown that parallel plasticity at two of these synapses can be used to tune neurons to different intervals (Buonomano, 2000). These previous data, together with the results presented here, emphasize that the full computational potential of neural circuits may rely on parallel modulation of different synaptic loci, rather than short- and long-term plasticity of the Input $\rightarrow$ Ex synapse alone.

Although we have focused on paired-pulse plasticity, we speculate that with longer trains of stimuli, there may be dynamic changes in the E-S shifts. One possibility is that PPD of the IPSPs would eventually offset the E-S depression produced by temporal overlap of a given EPSP with the preceding IPSP. Depending on changes in the relative balance of excitation and inhibition, attributable to PPF of the EPSPs, PPD of the IPSPs, and long-lasting inhibition, the E-S curve might start out shifted rightward for double pulses and move steadily leftward for later pulses in the train. This would act to amplify the output of later EPSPs while minimizing the output of earlier EPSPs.

\section{Conclusion}

Our results provide an example of how the same excitatory synaptic strengths can translate into different outputs. This occurs as a result of the dynamic balance between excitation and inhibition. Specifically, in the system studied here, inhibition can counteract short-term facilitation of excitatory synapses. Thus, to understand the functional effects of both short- and long-term synaptic plasticity, it is necessary to determine the net effect of parallel changes occurring at multiple synaptic loci.

\section{References}

Abbott LF, Varela JA, Kamal S, Nelson SB (1997) Synaptic depression and cortical gain control. Science 275:220-224.

Abraham WC, Bliss TVP, Goddard GV (1985) Heterosynaptic changes accompany long-term but not short-term potentiation of the perforant path in the anaesthetized rat. J Physiol (Lond) 363:335-349.

Abraham WC, Gustafsson B, Wigstrom H (1987) Long-term potentiation involves enhanced synaptic excitation relative to synaptic inhibition in guinea-pig hippocampus. J Physiol (Lond) 394:367-380.

Ali AB, Thomson AM (1998) Facilitating pyramid to horizontal oriensalveus interneurone inputs: dual intracellular recordings in slices of rat hippocampus. J Physiol (Lond) 507.1:185-199.

Ali AB, Deuchars J, Pawelzik H, Thomson AM (1998) CA1 pyramidal to basket and bistratified cell EPSPs: dual intracellular recordings in rat hippocampal slices. J Physiol (Lond) 507.1:201-217.

Andersen P, Bliss TVP, Skrede KK (1971) Unit analysis of hippocampal population spikes. Exp Brain Res 13:208-221.

Andersen P, Sundberg SH, Sveen O, Swann JW, Wigstrom H (1980) Possible mechanisms for long-lasting potentiation of synaptic transmission in hippocampal slices from guinea pigs. J Physiol (Lond) 302:463-482.

Bliss TVP, Gardner-Medwin AR (1973) Long-lasting potentiation of synaptic transmission in the dentate area of the unanaesthetized rabbit following stimulation of the perforant path. J Physiol (Lond) 232:357-374.

Bliss TVP, Lomo T (1973) Long-lasting potentiation of synaptic transmission in the dentate area of the anaesthetized rabbit following stimulation of the perforant path. J Physiol (Lond) 232:331-356.

Buonomano DV (2000) Decoding temporal information: a model based on short-term synaptic plasticity. J Neurosci 20:1129-1141.

Buonomano DV, Merzenich MM (1995) Temporal information transformed into a spatial code by a neural network with realistic properties. Science 267:1028-1030.

Buonomano DV, Merzenich MM (1998) Net interaction between different forms of short-term synaptic plasticity and slow-IPSPs in the hippocampus and auditory cortex. J Neurophysiol 80:1765-1774.

Burdette LJ, Gilbert ME (1995) Stimulus parameters affecting paired-pulse depression of dentate granule cell field potentials. I. Stimulus intensity. Brain Res 680:53-62.

Buzsaki G (1984) Feed-forward inhibition in the hippocampal formation. Prog Neurobiol 22:131-153.

Chavez-Noriega LE, Bliss TVP, Halliwell JV (1989) The EPSP-spike (E-S) component of long-term potentiation in the rat hippocampal slice is modulated by GABAergic but not cholinergic mechanisms. Neurosci Lett 104:58-64.

Cowan AI, Stricker C, Reece LJ, Redman SJ (1998) Long-term plasticity at excitatory synapses on aspinous interneurons in area CA1 lacks synaptic specificity. J Neurophysiol 79:13-20.

Davies CH, Davies SN, Collingridge GL (1990) Paired-pulse depression of monosynaptic GABA-mediated inhibitory postsynaptic responses in rat hippocampus. J Physiol (Lond) 424:513-531.

Fisher SA, Fischer TM, Carew TJ (1997) Multiple overlapping processes underlying short-term synaptic enhancement. Trends Neurosci 20:170-177.

Freund TF, Buzsaki G (1996) Interneurons of the hippocampus. Hippocampus 6:347-470.

Fukuda A, Mody I, Prince DA (1993) Differential ontogenesis of presynaptic and postsynaptic $\mathrm{GABA}_{\mathrm{B}}$ inhibition in rat somatosensory cortex. J Neurophysiol 70:448-453. 
Galarreta M, Hestrin S (1998) Frequency-dependent synaptic depression and the balance of excitation and inhibition in the neocortex. Nat Neurosci 1:587-594.

Haas HL, Rose G (1982) Long-term potentiation of excitatory synaptic transmission in the rat hippocampus: the role of inhibitory processes. J Physiol (Lond) 329:541-552.

Hajos N, Nusser Z, Rancz EA, Freund TF, Mody I (2000) Cell type- and synapsE-Specific variability in synaptic $\mathrm{GABA}_{\mathrm{A}}$ receptor occupancy. Eur J Neurosci 12:810-818.

Jester JM, Campbell LW, Sejnowski TJ (1995) Associative EPSP-spike potentiation induced by pairing orthodromic and antidromic stimulation in rat hippocampal slices. J Physiol (Lond) 484.3:689-705.

Jiang L, Sun S, Nedergaard M, Kang J (2000) Paired-pulse modulation at individual GABAergic synapses in rat hippocampus. J Physiol (Lond) 523.2:425-439.

Kairiss EW, Abraham WC, Bilkey DK, Goddard GV (1987) Field potential evidence for long-term potentiation of feed-forward inhibition in the rat dentate gyrus. Brain Res 401:87-94.

Karnup S, Stelzer A (1999) Temporal overlap of excitatory and inhibitory afferent input in guinea-pig CA1 pyramidal cells. J Physiol (Lond) 516.2:485-504.

Leung LS, Au AS (1994) Long-term potentiation as a function of test pulse intensity: a study using input/output profiles. Brain Res Bull 33:453-460.

Leung LS, Fu X-W (1994) Factors affecting paired-pulse facilitation in hippocampal CA1 neurons in vitro. Brain Res 650:75-84.

Lu YM, Mansuy IM, Kandel ER, Roder J (2000) Calcineurin-mediated LTD of GABAergic inhibition underlies the increased excitability of CA1 neurons associated with LTP. Neuron 26:197-205.

Maccaferri G, McBain CJ (1996) Long-term potentiation in distinct subtypes of hippocampal nonpyramidal neurons. J Neurosci 16:5334-5343.

Maccaferri G, Roberts JDB, Szucs P, Cottingham CA, Somogyi P (2000) Cell surface domain specific postsynaptic currents evoked by identified GABAergic neurones in rat hippocampus in vitro. J Physiol (Lond) 524.1:91-116.

MacDonald RL, Meldrum BS (1989) Principles of antiepileptic drug action. In: Antiepileptic drugs, Ed 3 (Levy RH, Dreifuss FE, Mattson RH, Meldrum BS, Penry JK, eds), pp 59-83. New York: Raven.

McMahon LL, Kauer JA (1997) Hippocampal interneurons express a novel form of synaptic plasticity. Neuron 18:295-305.

Mody I, DeKoninck Y, Otis TS, Soltesz I (1994) Bridging the cleft at GABA synapses in the brain. Trends Neurosci 17:517-525.

Mott DD, Xie CW, Wilson WA, Swartzwelder HS, Lewis DV (1993)
$\mathrm{GABA}_{\mathrm{B}}$ autoreceptors mediate activity-dependent disinhibition and enhance signal transmission in the dentate gyrus. J Neurophysiol 69:674-691.

Otis TS, Mody I (1992) Modulation of decay kinetics and frequency of $\mathrm{GABA}_{\mathrm{A}}$ receptor-mediated spontaneous inhibitory postsynaptic currents in hippocampal neurons. Neuroscience 49:13-32.

Ouardouz M, Lacaille JC (1995) Mechanisms of selective long-term potentiation of excitatory synapses in stratum oriens/alveus interneurons of rat hippocampal slices. J Neurophysiol 73:810-819.

Patenaude C, Nurse S, Lacaille JC (2001) Sensitivity of synaptic GABA A receptors to allosteric modulators in hippocampal oriens-alveus interneurons. Synapse 41:29-39.

Perez Y, Morin F, Lacaille JC (2001) A Hebbian form of long-term potentiation dependent on mGluRla in hippocampal inhibitory interneurons. Proc Natl Acad Sci USA 98:9401-9406.

Pouille F, Scanziani M (2001) Enforcement of temporal fidelity in pyramidal cells by somatic feed-forward inhibition. Science 293:1159-1163.

Stelzer A, Simon G, Kovacs G, Rai R (1994) Synaptic disinhibition during maintenance of long-term potentiation in the CA1 hippocampal subfield. Proc Natl Acad Sci USA 91:3058-3062.

Taube JS, Schwartzkroin PA (1988) Mechanisms of long-term potentiation: EPSP/spike dissociation, intradendritic recordings, and glutamate sensitivity. J Neurosci 8:1632-1644.

Tsodyks M, Uziel A, Markram H (2000) Synchrony generation in recurrent networks with frequency-dependent synapses. J Neurosci 20(RC50):1-5.

Tuff LP, Racine RJ, Adamec R (1983) The effects of kindling on GABAmediated inhibition in the dentate gyrus of the rat. I. Paired-pulse depression. Brain Res 277:79-90.

Wathey JC, Lytton WW, Jester JM, Sejnowski TJ (1992) Computer simulations of EPSP-spike (E-S) potentiation in hippocampal CA1 pyramidal cells. J Neurosci 12:607-618.

Wilson RC, Levy WB, Steward O (1981) Changes in translation of synaptic excitation to dentate granule cell discharge accompanying long-term potentiation. II. An evaluation of mechanisms utilizing dentate gyrus dually innervated by surviving ipsilateral and sprouted crossed temporodentate inputs. J Neurophysiol 46:339-355.

Xie Z, Yip S, Morishita W, Sastry BR (1995) Tetanus-induced potentiation of inhibitory postsynaptic potentials in hippocampal CAl neurons. Can J Physiol Pharmacol 73:1706-1713.

Yoon KW, Rothman SM (1991) The modulation of rat hippocampal synaptic conductances by baclofen and gamma-amino-butyric acid. J Physiol (Lond) 442:377-390. 